\title{
Thermal behavior of a microdevice under transient heat loads
}

\author{
Saptarshi Basu, ${ }^{\mathrm{a}, *}$, Brian Werneke, Yoav Peles ${ }^{\mathrm{b}}$, Michael K. Jensen \\ Department of Mechanical, Aerospace, and Nuclear Engineering, Rensselaer Polytechnic \\ Institute, Troy, NY, 12180 \\ ${ }^{a}$ Dielectric Systems Module, Applied Materials, Santa Clara, CA, 95054 \\ ${ }^{b}$ Department of Mechanical and Aerospace Engineering, University of Central Florida, \\ Orlando, FL 32816
}

\begin{abstract}
An experimental study was carried out to investigate the transient response of a thermal microsystem to both a step change and a square wave pulse change in heat flux. The microsystem consisted of a single microchannel etched on a silicon microdevice that was bonded to a Pyrex wafer. A thin-film titanium heater was deposited on the Pyrex substrate. The heater acted as the power source as well as the resistance temperature device. The influence of flow convection on the transient response was studied for two fluids: air and HFE-7000. The effects of heat flux, Reynolds number, fluid properties, and pulse parameters (amplitude, width, duty cycle) on the transient temperature response were identified. The temperature response consisted of an initial rapid temperature rise followed by slower convection dynamics. For longer pulse widths, the temperature of the microdevice reached steady state. Higher order dynamics were identified at the beginning of the temperature response. Convection dynamics were approximated as a first-order response, and the effects of Reynolds number and fluid properties on the time constant of the first order response were identified.
\end{abstract}

Keywords:

Transient, Microscale, Pulse, Step Change in Heat Flux, Air, HFE-7000

\footnotetext{
*Corresponding Author: basu.saptarshi@gmail.com
}

Preprint submitted to International Journal of Heat and Mass Transfer August 9, 2015 


\section{Nomenclature}

$\begin{array}{ll}q^{\prime \prime} & \text { Heat Flux, } W / m^{2} \\ \text { Re } & \text { Reynolds Number } \\ T & \text { Temperature, } K \\ \text { Greek Letters } & \\ \tau & \text { Pulse Width } \\ \text { Subscripts } & \\ c & \text { Constant } \\ \text { heater } & \text { Heater } \\ \text { ss } & \text { Steady-state } \\ w p & \text { Waiting period }\end{array}$




\section{Introduction}

High temperatures and temperature transients in electronic devices are the leading causes of poor performance, low reliability, and high failure rates. Thermal management of electronic systems requires efficient dissipation of heat in order to maintain the device temperatures within acceptable limits. Due to varying loads and demands as well as unwanted fluctuations, the power profile encountered in electronic systems frequently vary with time. Transients are typically applied in the form of a step input, pulse input or impulse input [1]. Temperature cycling due to these transients adversely affects the performance, properties, and signal integrity of the device. An efficient cooling system should be able to maintain an isothermal environment and minimize temperature fluctuations while operating under high frequency transient loads [2]. Design and control of heat sinks and heat exchangers operating under unsteady conditions require a detailed understanding and knowledge of transient heat transfer characteristics.

Several analytical [3-5] and numerical studies [6-16] have been performed at the macroscale to understand the parametric trends governing the transient response of a thermal system to an applied unsteady boundary condition. The thermal system was either a thick walled circular pipe $[3,5,7,8,11]$ or parallel flat plates $[4,5,12-14,16]$. Transient boundary conditions were introduced in the form of a step change in heat flux [11] or a step change in temperature (outside wall [7] or ambient $[6,10]$ or inlet $[4,5,13]$ ). Yan [16] numerically investigated conjugate transient heat transfer in turbulent infinitely long channel with ambient convection. With increased availability of computing resources, sophisticated numerical models were developed to include conjugate effects, wall thickness, transverse and axial conduction in the solid and fluid in the analysis of unsteady heat transfer. Wall-to-fluid conductivity ratio, wall-to-fluid thermal diffusivity ratio, dimensionless wall thickness ratio, Reynolds number, Prandtl number, and the dimensionless cooling length were instrumental in defining the conjugate transient heat transfer characteristics of the system [16]. Morega et al. [17] undertook an analytical, numerical, and experimental study to determine the optimal pulse frequency for forced convection in an external flow situation. The main idea

was to tune the pulse frequency with the natural convection time scale of the flow to optimize the thermal contact between the heated wall and the fluid. The numerical study was carried out for a flat plate while experiments were conducted using a cylindrical heater. The effects of pulsed heating on 
single-phase heat transfer for internal flows were not investigated.

A few studies investigated transient heat transfer characteristics in MEMS based thermal microsystems [18-20] using numerical models. The effects of different substrate materials, geometrical dimensions (length, channel width and depth), and thermal properties (thermal conductivity and specific heat) on the time response of the thermal microsystem to a step change in boundary conditions were investigated. Jiang et al. [2, 21] conducted experimental studies to determine the transient heat transfer characteristics of an integrated microsystem. Deionized water was used as the test fluid. Transient response to a step current input and sinusoidal power input was investigated for different power levels and flow rates. Heating rise time and cooling fall time were determined for natural convection (dry) as well as forced convection (wet) case under a step current input. The step response for natural convection was exponential for both heating and cooling process. Response time was four times faster for the forced convection case, while the heating time response showed a significant overshobbot over the steady-state temperature $[2,21]$. This was not captured in previous numerical simulations $[2,21]$. The heating time constant was greater than the cooling time constant. Temperature response to the sinusoidal power input was governed by three parameters, namely the frequency, peak-to-peak voltage, and the average voltage level. The frequency used in the experiments was in the $\mathrm{mHz}$ range. The heater was located at the inlet to the channels, while the temperature sensors were located above the channels to monitor the device temperatures [2, 21].

Only a couple of experimental studies were conducted to investigate transient heat transfer characteristics in a microsystem. Deionized water was the test fluid. Most studies were limited to understanding the transient heat transfer characteristics for a step change in heat input but the transient response to a pulsed heat input was not investigated. In the present work, air and HFE-7000 were used as test fluids. HFE-7000 is a low global warming potential engineered heat transfer fluid. It can be used as a refrigerant. Single-phase heat transfer characteristics of a microchannel heat sink were studied for transient heat input that was applied as a step change in heat flux and square pulse of millisecond width. The effects of heat flux (0.1-6.75 $\mathrm{MW} / \mathrm{m}^{2}$ ), Reynolds number (100-4000), and fluid properties (Prandtl number, thermal conductivity) on transient heat transfer characteristics of the microsystem were investigated over different pulse widths (1-3000 ms). 


\section{Experimental Apparatus and Data Acquisition}

Single-phase heat transfer experiments were conducted in a microchannel heat sink with air and HFE-7000. The test rig comprised of an open flow loop for air (Fig. 1) and a closed flow loop for HFE-7000 [22]. Compressed facility air was used for the air experiments. The air flow was conducted through pressure regulators and valves to control the flow rate. The closed flow loop comprised of a condenser, preheater, and an auxiliary heat exchanger that were used to control the fluid inlet temperature. A pressure vessel that stored HFE-7000 was added to the closed flow loop [22].

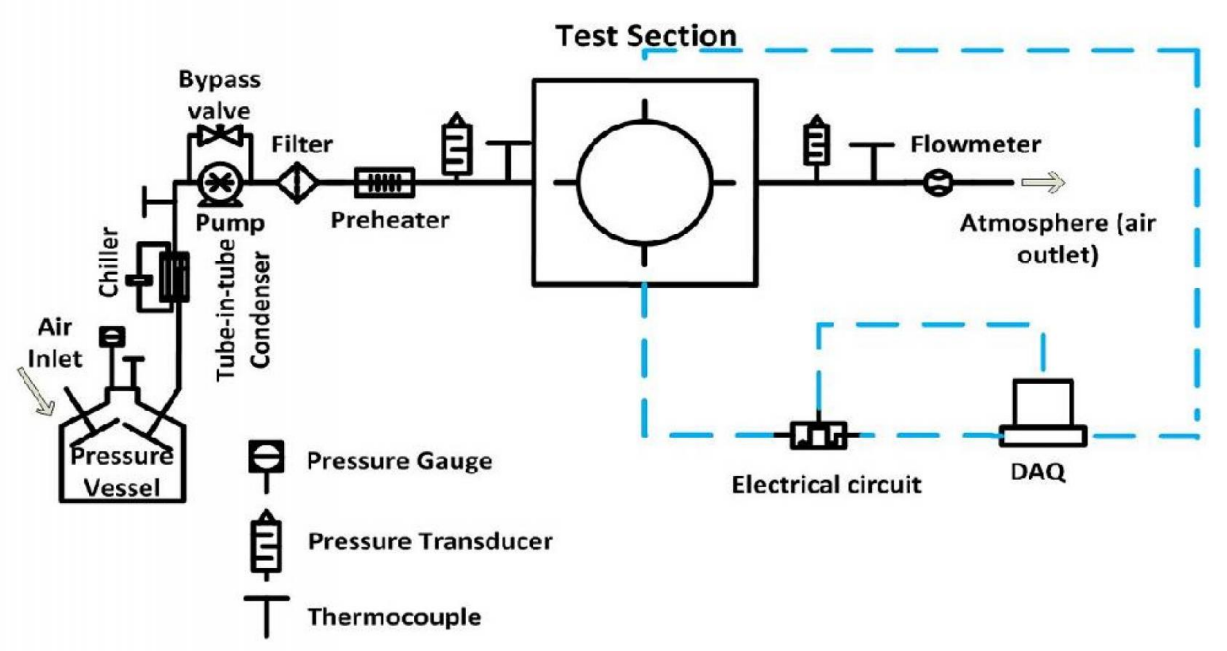

Figure 1: Schematic of the open flow loop for air experiments

An array of thermocouples and pressure transducers were used to monitor the temperature and pressure at different locations in the test rig. A microchannel $(10 \mathrm{~mm} \times 1.2 \mathrm{~mm} \times 0.2 \mathrm{~mm})$ was etched in a silicon microdevice that was bonded to a Pyrex wafer. The microdevice was square shaped with a side length of $20 \mathrm{~mm}$. The thickness of the silicon wafer was $0.45 \mathrm{~mm}$ and that of the Pyrex wafer was $1.0 \mathrm{~mm}$. A $1 \mathrm{~mm} \times 1 \mathrm{~mm}$ titanium thin 
film heater was deposited on the Pyrex wafer. The heater was located on the bottom surface of the Pyrex substrate and was in direct contact with the fluid in the microchannel (Fig. 2). The Pyrex wafer was bonded to the Silicon wafer but the heater was placed over the microchannel gap. The heater acted as a temperature sensor whose resistance changed with temperature change in response to fluid flow. The microdevice was housed in a Delrin fixture (Fig. 3) with fluid conduits that connected the microdevice to the test rig. A SEM image of the silicon microchannel is shown in Fig. 4. Further details about the microfabrication process and the microdevice is available in Browne [23]. A detailed description of the flow loop, microdevice, and experimental procedures are given in Basu [24, 22].

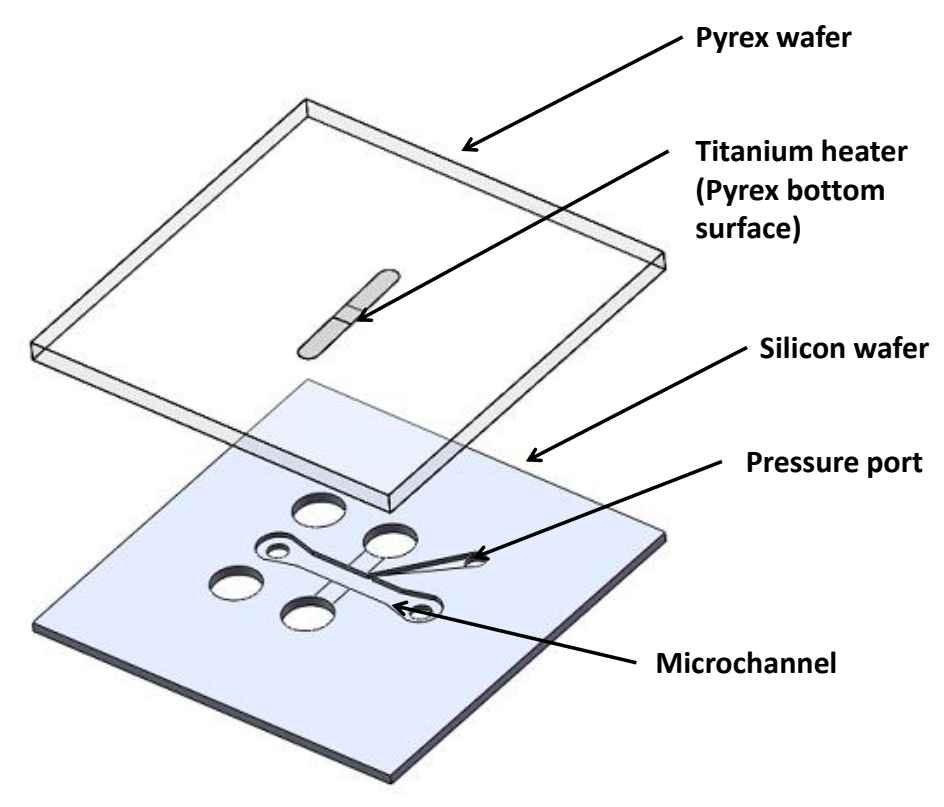

Figure 2: Exploded view of the microdevice

Heater resistance linearly varied with the heater temperature with a negative slope. A similar trend was also observed in Avedisian et al. [25] and Browne [23]. The heater resistance was calculated using Ohm's law. Voltage 


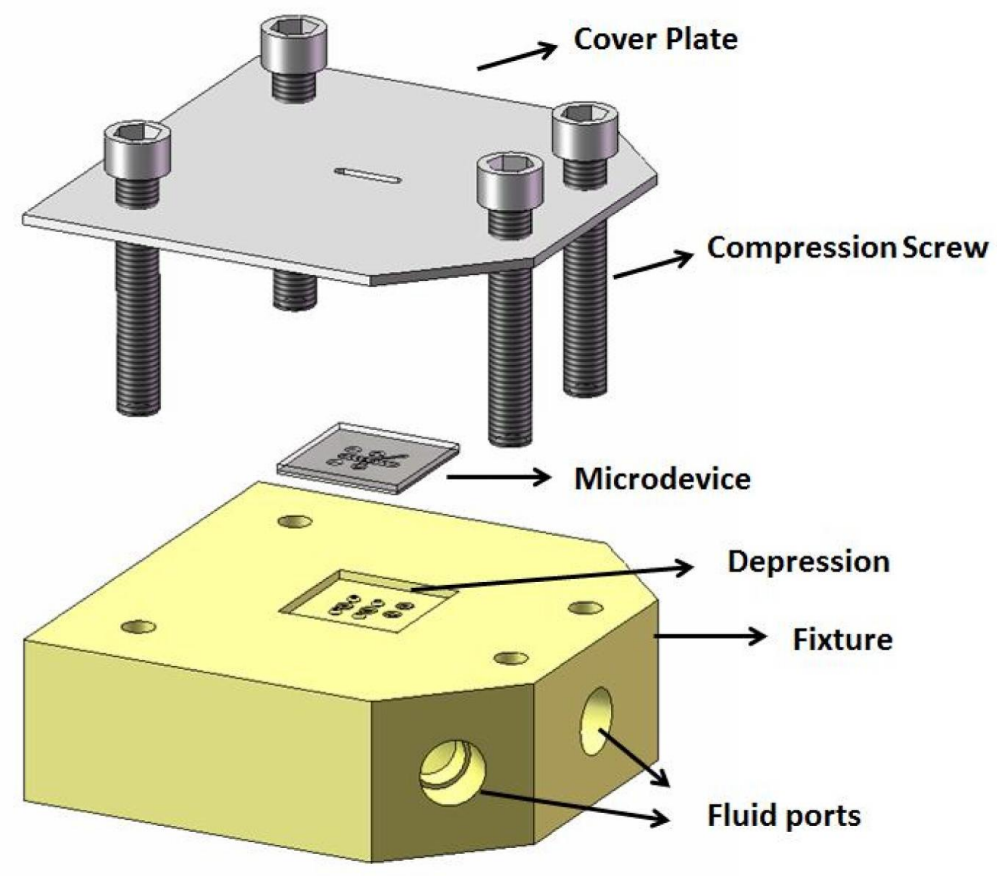

Figure 3: Exploded view of the cover plate, microdevice, and Delrin fixture [23] and current were measured using two independent oscilloscopes. 


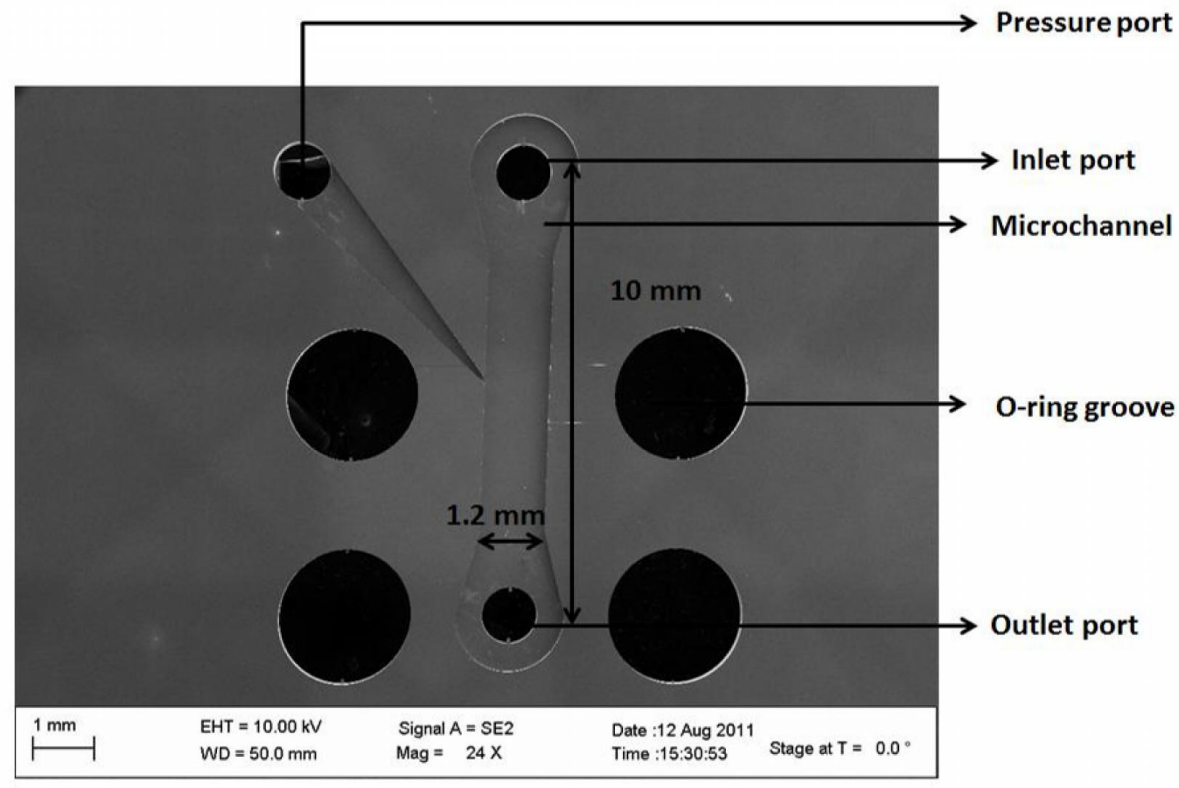

Figure 4: SEM of silicon wafer [23]

The data acquisition system (DAQ) comprised of NI LabVIEW hardware and software that was synchronized with the two oscilloscopes (Tektronix TDS2012B and TDS2022B), pulse generator, high-speed camera (Vision Research Phantom V4.2) and a DC power source (Sorensen DLM 600-5E). High frequency transient measurements of the current and voltage as well as the camera images were synchronized with the power pulse using a MOSFET based switching circuit ([22]).

The uncertainties in the derived quantities were calculated from the uncertainty in the measured quantities using the propagation of uncertainty method outlined in Kline and McClintock [26]. The uncertainties in mass flux $\left(\mathrm{kg} / \mathrm{m}^{2}-\mathrm{s}\right)$, heater temperature $(\mathrm{K})$, and heat flux $\left(\mathrm{W} / \mathrm{m}^{2}\right)$ are $\pm 5.2 \%$, $\pm 1.5 \%$, and $\pm 1.0 \%$, respectively. Details of the uncertainty analysis are available in Basu [24]. 


\subsection{Measurement Considerations}

A detailed description of the measurement considerations is provided in Basu et al. [22] and Basu [24]. The heater temperature was correlated to its resistance that was based on current and voltage measurements. The transient electrical power delivered to the heater was also calculated based on the transient current and voltage measurements. The heater was heated due to Joule heating. Heat flux was calculated by dividing the electrical power with the heater surface area. The heat flux was dissipated by conduction through the Pyrex substrate and convection as well as conduction through the fluid. However, the exact distribution of the heat flux was not determined in the present study.

The thermal inertia of the $100 \mathrm{~nm}$ thick heater is very small. There is a rapid temperature rise at the beginning of the transient due to the small thermal inertia. With increasing heater temperature, convection effects became dominant as the wall-to-fluid temperature difference increased. The oscilloscopes had limited sampling rate that was not enough to accurately capture the rapid temperature rise at the beginning of the transient. There was a voltage spike at the starting edge of the square pulse when the power supply is switched on. Avedisian et al. [25] attributed this to a variety of factors like inductive pickup or high frequency cycling. This resulted in erroneous measurements during the initial transients. The time scale of this artifact depended on the sampling frequency of the oscilloscope and generally lasted for less than $1 \%$ of the total time period [24]. These initial data points were not considered in the plots presented in this paper. The data were filtered using the Butterworth filter of order one to smooth the plot and remove noise.

\section{Results and Discussion}

A series of experiments were carried out to study the effects of heat flux, Reynolds number, Prandtl number, and pulse parameters (pulse amplitude and width) on the transient temperature response of the heater. The heater response was studied for forced convection of air and HFE-7000. The convection dynamics were measured in terms of the time constant of the system. The transient heat load was introduced in the form of a step change in heat

flux and a square wave pulsed power. A detailed discussion of the results is presented here. 


\subsection{Transient response to a step change in heat flux}

\subsubsection{Effects of heat flux}

The effects of heat flux on the temperature response of the heater are shown in Fig. 5 (air) and Fig. 6 (HFE-7000).

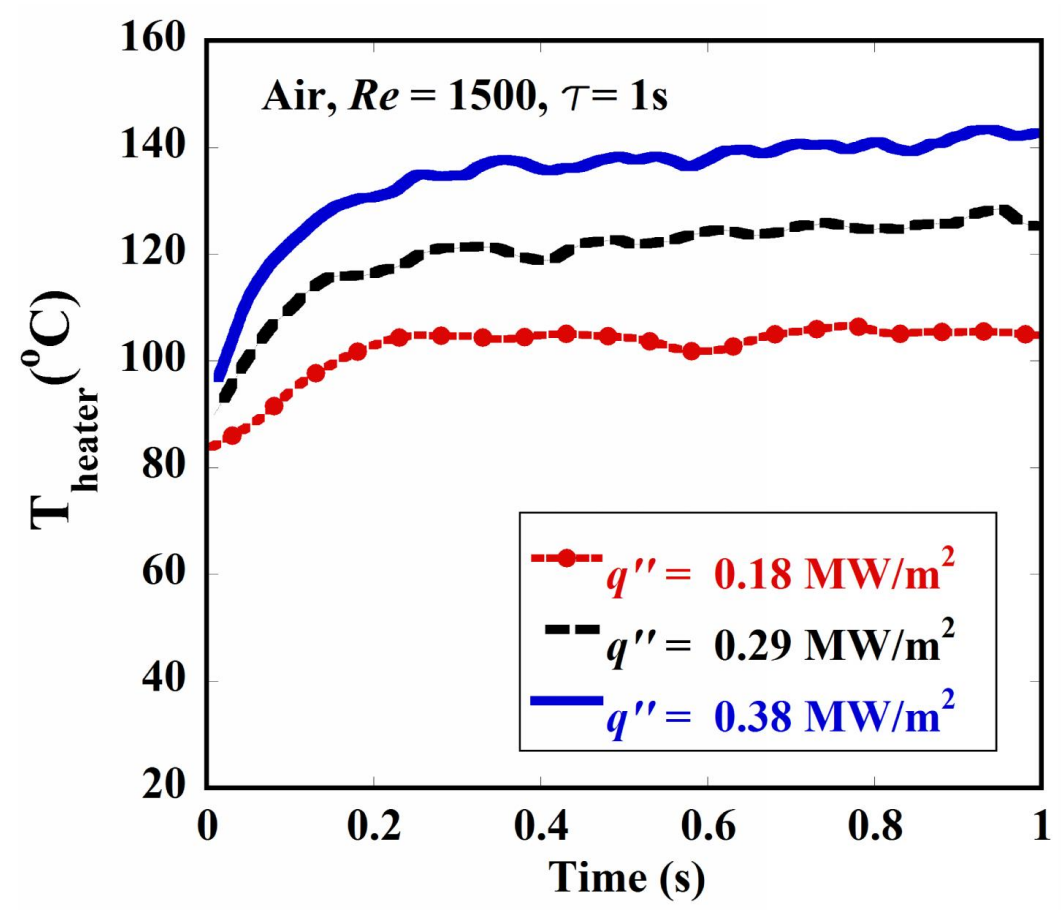

Figure 5: Effects of heat flux on heater temperature response for forced convection of air

Steady-state temperature increased with increasing heat flux. Due to the small heater size, although the supplied heat flux was high, the actual power was miniscule and, therefore, the fluid temperature change was minimal. The initial temperature dynamics were dominated by conduction before convection effects set in. Although the sampling rate of the DAQ system was not fast enough to accurately capture the rate of temperature rise in the conduction dominated regime (of the order of $10^{3 \circ} \mathrm{C} / \mathrm{s}$ ), it does indicate that the rate of temperature change was faster compared to that in the convection dominated regime (of the order of $10-50^{\circ} \mathrm{C} / \mathrm{s}$ ).

For constant fluid properties and temperatures, the temperature of the 


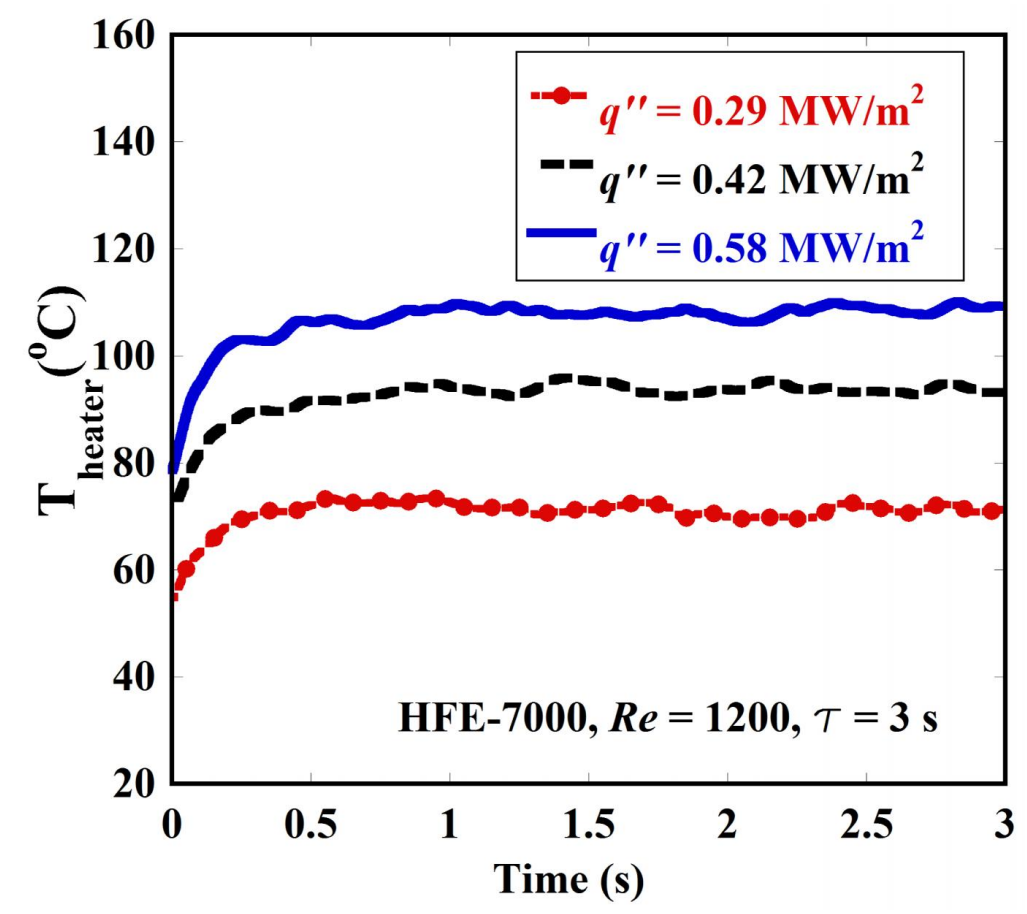

Figure 6: Effects of heat flux on heater temperature response for forced convection of HFE-7000

heater during conduction dominated heat transport is governed by the applied heat flux, fluid thermal conductivity, and conductivity of the Pyrex. The Pyrex conductivity remains unchanged in the experiment. Thus, a higher heat flux resulted in a higher temperature rise before convection effects set in for all three cases. For HFE-7000 experiments (Fig. 6), although the applied heat flux was higher compared to the air experiments, the higher thermal conductivity of the liquid resulted in lower heater temperature before convection effects set in. It should be noted that the air data are for Re $=1500$ and the HFE-7000 data are for $R e=1200$.

\subsubsection{Effects of Reynolds number}

The effects of Reynolds number or mass flux on the temperature response of the heater is shown Fig. 7 (air) and Fig. 8 (HFE-7000). The Reynolds number was defined with respect to the hydraulic diameter of the microchannel. The hydraulic diameter of the microchannel is $0.34 \mathrm{~mm}$. The flow was 
always thermally developing over the heater. For laminar flow, the hydrodynamic boundary layer was fully developed for Reynolds number less than 700 but at higher Reynolds number, it was hydrodynamically developing.

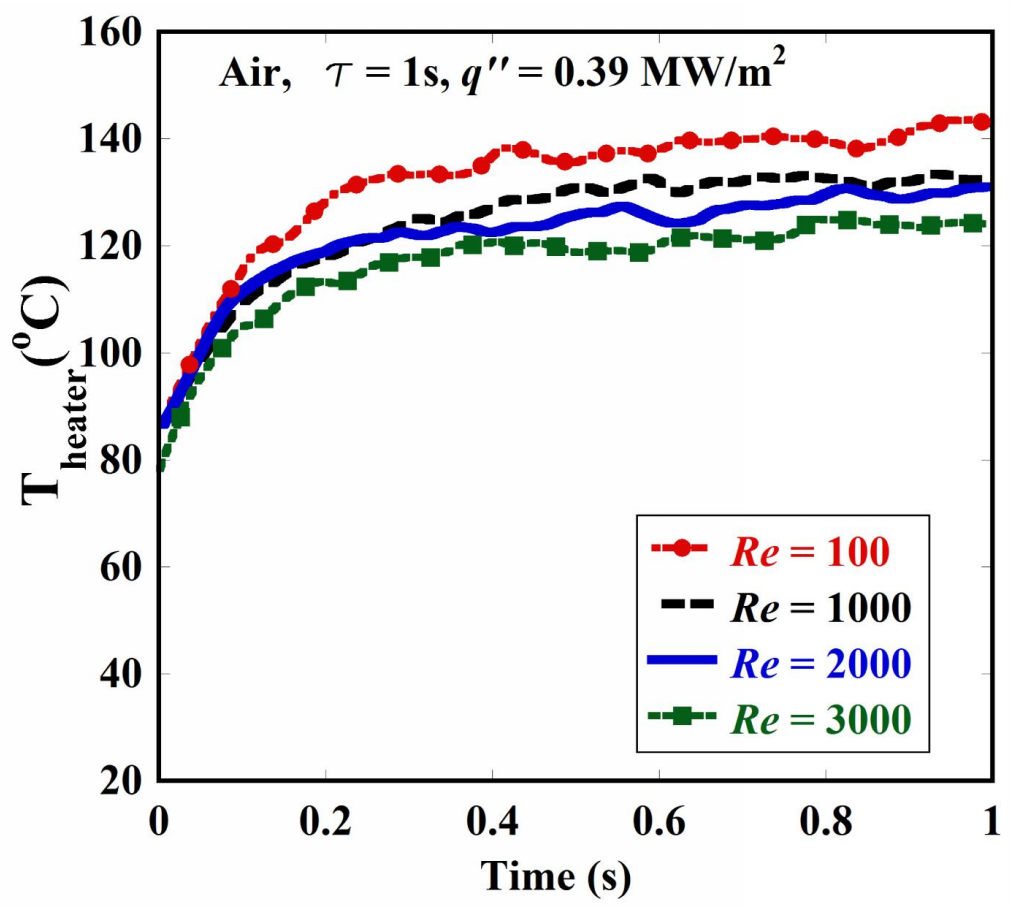

Figure 7: Effects of Reynolds number on heater temperature response for forced convection of air

Steady-state temperatures decreased with increasing Reynolds number. Convective cooling was more pronounced with HFE-7000 than with air. In Fig. 8, the decrease in steady-state temperature with Reynolds number was more pronounced during laminar flow (low Reynolds number) than in the transition or turbulent regime. In both cases, the rate of initial temperature rise and the temperature of the heater at which convection effects set in were not affected significantly by variations in Reynolds number, further indicating that the initial temperature response was a conduction dominated process. 


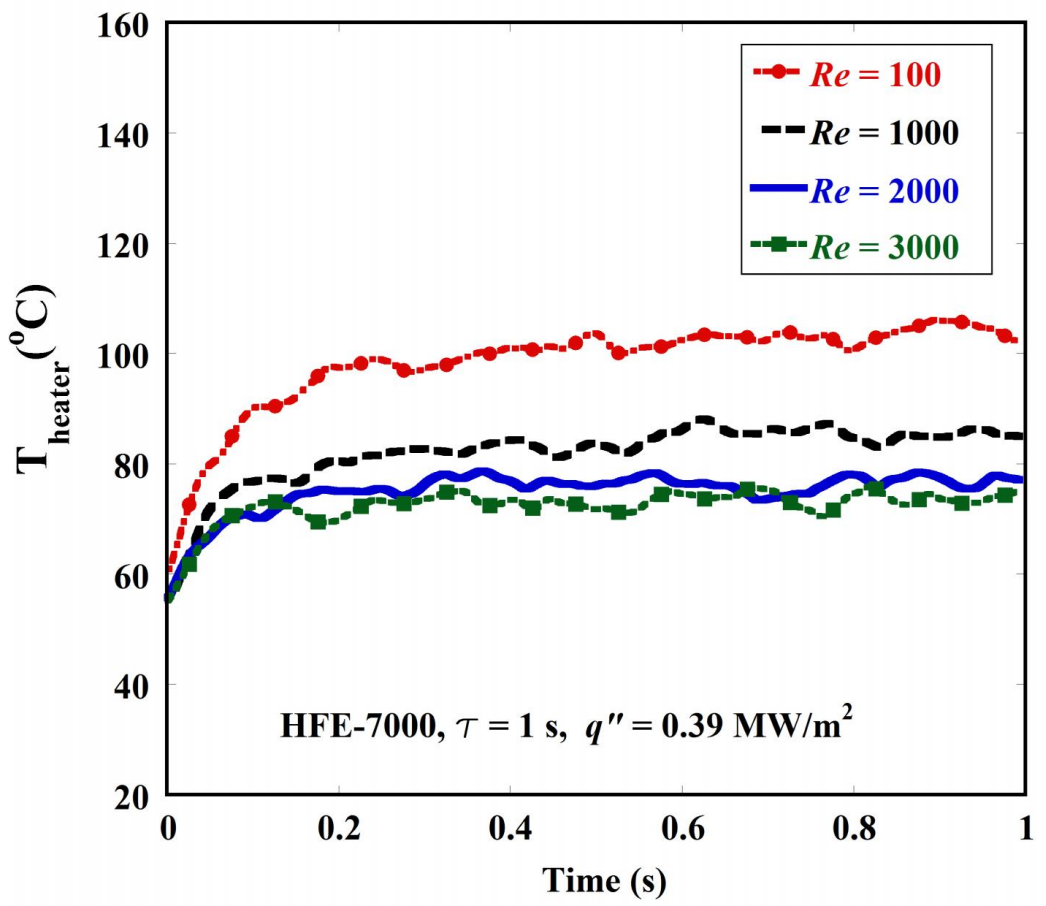

Figure 8: Effects of Reynolds number on heater temperature response for forced convection of HFE-7000

\subsubsection{Effects of fluid properties}

Higher thermal conductivity of HFE-7000 $(\mathrm{k}=0.075 \mathrm{~W} / \mathrm{m}-\mathrm{K})$ compared to air $(\mathrm{k}=0.026 \mathrm{~W} / \mathrm{m}-\mathrm{K})$ led to higher heat transfer coefficients and lower temperatures for HFE-7000 for the same mass flux and heat flux (Fig. 9). Prandtl number of HFE-7000 ( $\mathrm{Pr}=7.76)$ was about ten times larger than that of air $(\mathrm{Pr}=0.695)$. The total applied heat flux was the same for both air and HFE-7000 experiments, but the heat flux transferred to the fluid was higher for HFE-7000 due to its stronger convective effect. The initial temperature rise due to conduction was lower for HFE-7000 than for air.

The effects of mass flux and heat flux on steady-state temperatures for different fluids and convective boundary conditions are shown in Fig. 10 and Fig. 11, respectively. HFE-7000 displayed better performance compared to air and the steady-state temperatures were lower. Steady-state temperatures increased as a weak non-linear function of the applied heat flux. The non-linearity was due to the fact that the current in response to the applied 


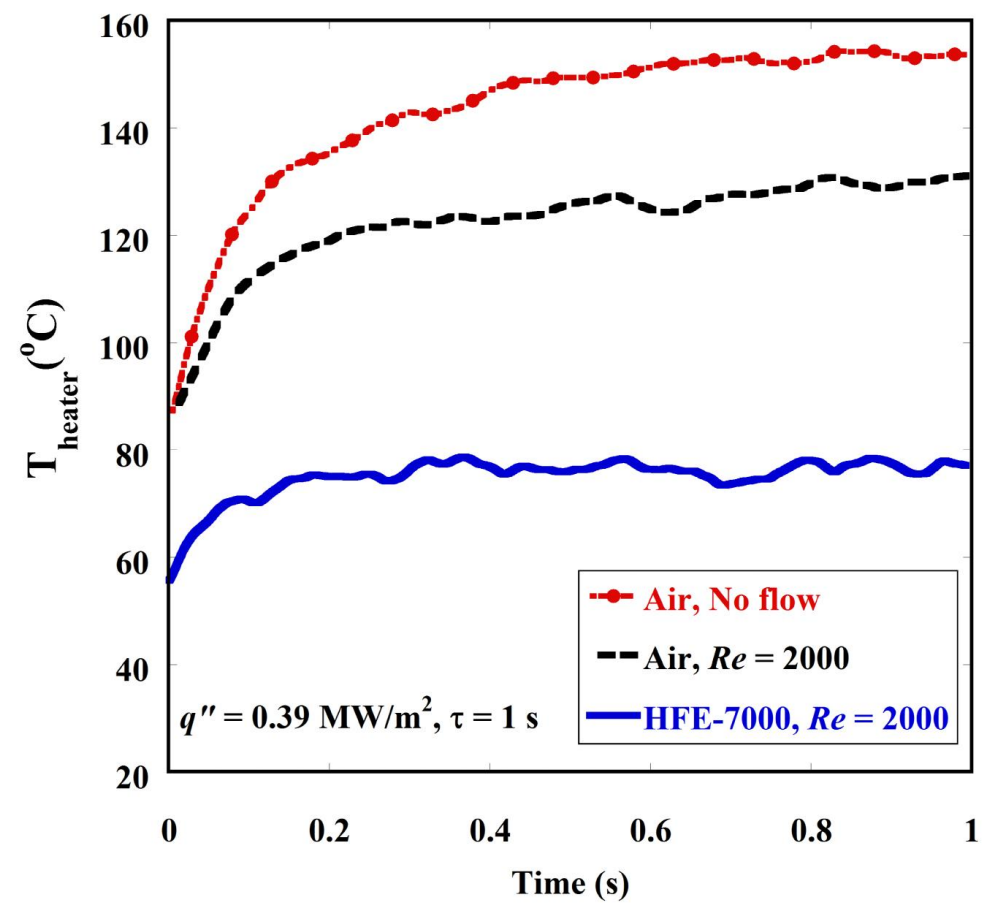

Figure 9: Effects of different fluids and convective boundary conditions on heater temperature response

voltage was determined by the resistance of the heater, which was a function of the heater temperature. Therefore, the applied power was also dependent on the heater temperature. The slope of the curve was determined by convection heat transfer coefficients and thermal properties of the fluid and the Pyrex substrate.

Increasing mass flux resulted in a decrease in steady-state temperature for both fluids. Steady-state temperatures were lower for HFE-7000 compared to air for the same Reynolds number. For the same change in Reynolds number, the decrease in steady-state temperature was higher for HFE-7000. For air, the rate of decrease in the steady temperature was uniform across all Reynolds numbers. For HFE-7000, the rate of decrease was higher at low Reynolds number. 


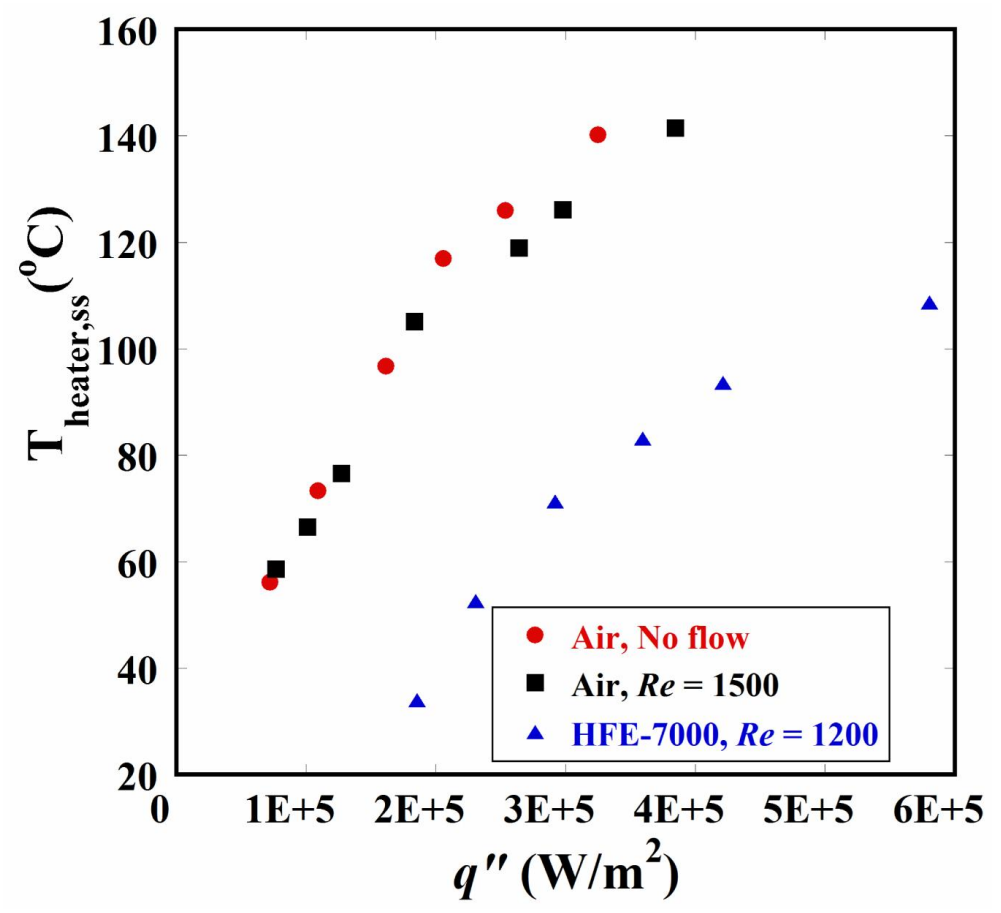

Figure 10: Effects of heat flux on the steady-state temperature of the heater for different operating conditions 


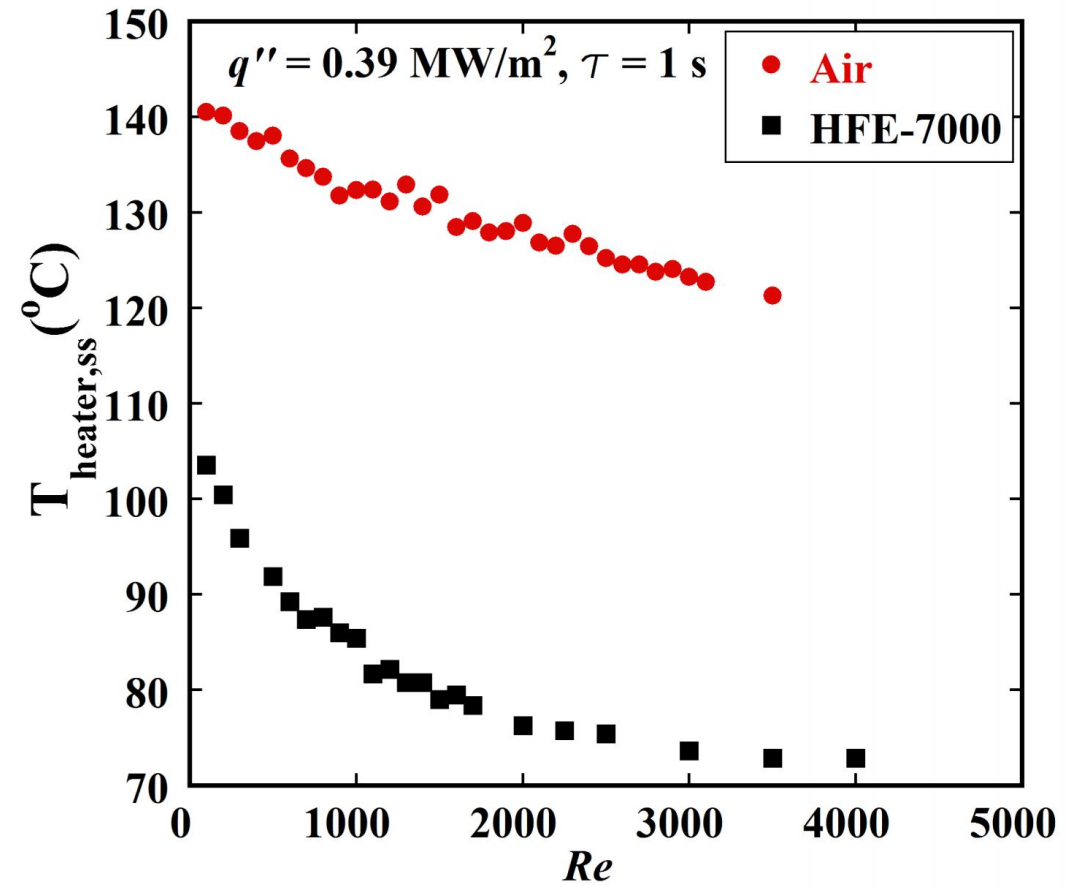

Figure 11: Effects of Reynolds number on the steady-state temperature of the heater for different operating conditions 


\subsubsection{Convection temperature dynamics}

The transient temperature response of the heater to a step input in heat flux can be divided into three stages: initial rapid conduction temperature rise, slower convection dynamics, and steady-state temperature. The initial conduction temperature rise defined the temperature at which convection effects set in. The temperature rise is determined approximately from the temperature plots. Convection dynamics exhibit an exponential type growth from the initial temperature (after conduction rise) to the final steady-state temperature. Ignoring higher-order dynamics, the convection dynamics can be modeled as a first-order system. The time constant of a first order system gives an idea of how fast a system will respond to a change in state [2]. Mass flux and fluid properties affect the time constant of the system. In this problem, the time constant is defined as the time taken for the system temperature response to reach $63.2 \%$ of the total change in temperature. The total temperature change was from the temperature at which convection effects set in to the final steady-state temperature. The physical properties of the heater and Pyrex substrate also affected the time constant but remained unchanged in the experiments. The effects of Reynolds number variation on the time constant for air and HFE-7000 are shown in Fig. 12.

Time constant decreased slightly with increasing Reynolds number due to increased heat transfer coefficients with increasing mass flux. The time constant also decreased by a factor of two to three for HFE-7000 compared to air as the former exhibited higher heat transfer coefficients. The plots presented in Fig. 12 should be considered for their trend rather than the actual value of the time constant. This is due to the uncertainties associated with accurately measuring the initial temperature transients. 


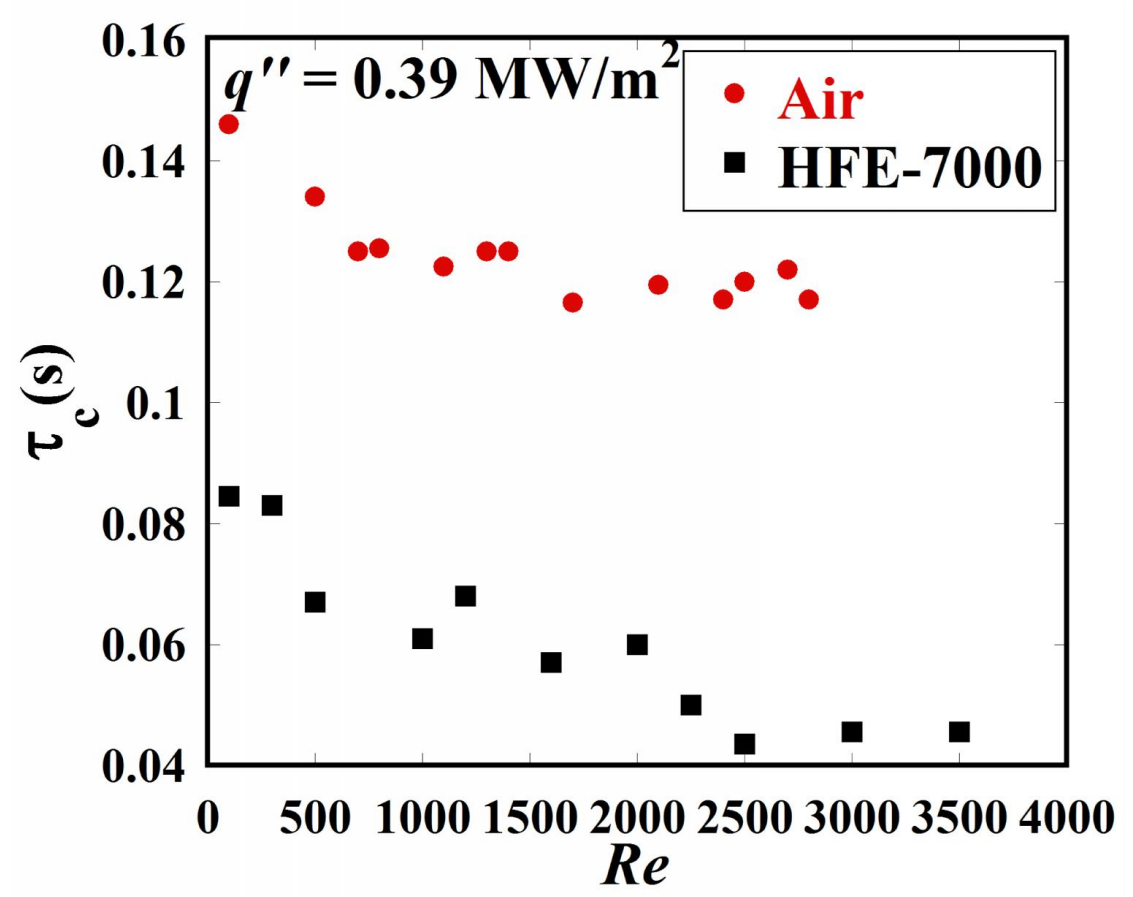

Figure 12: Effects of Reynolds number variation on time constant for air and HFE7000

\subsection{Transient response to pulsed heat input}

The total energy supplied to the thin-film heater is a product of the pulse amplitude and the pulse width. A step change input is a special case of a rectangular pulse with a pulse width long enough for the microsystem to reach a steady temperature. In the pulsed study, the heat flux was applied for a period of $1 \mathrm{~ms}$ or in that order of magnitude. Due to the shorter pulse width, higher pulse amplitude (heat flux) could be applied safely. The effects of pulse amplitude, Reynolds number, pulse width, and pulse waiting period on the temperature dynamics were determined, and the results are presented here.

\subsubsection{Effects of pulse amplitude}

The effects of pulse amplitude on the heater temperature response are shown in Fig. 13 and Fig. 14 for air and HFE-7000, respectively. The heater temperature increased with increasing pulse amplitude. The applied 
heat flux also affected the temperature dynamics. The heat was dissipated via conduction through the fluid and the Pyrex substrate as well as by fluid convection.

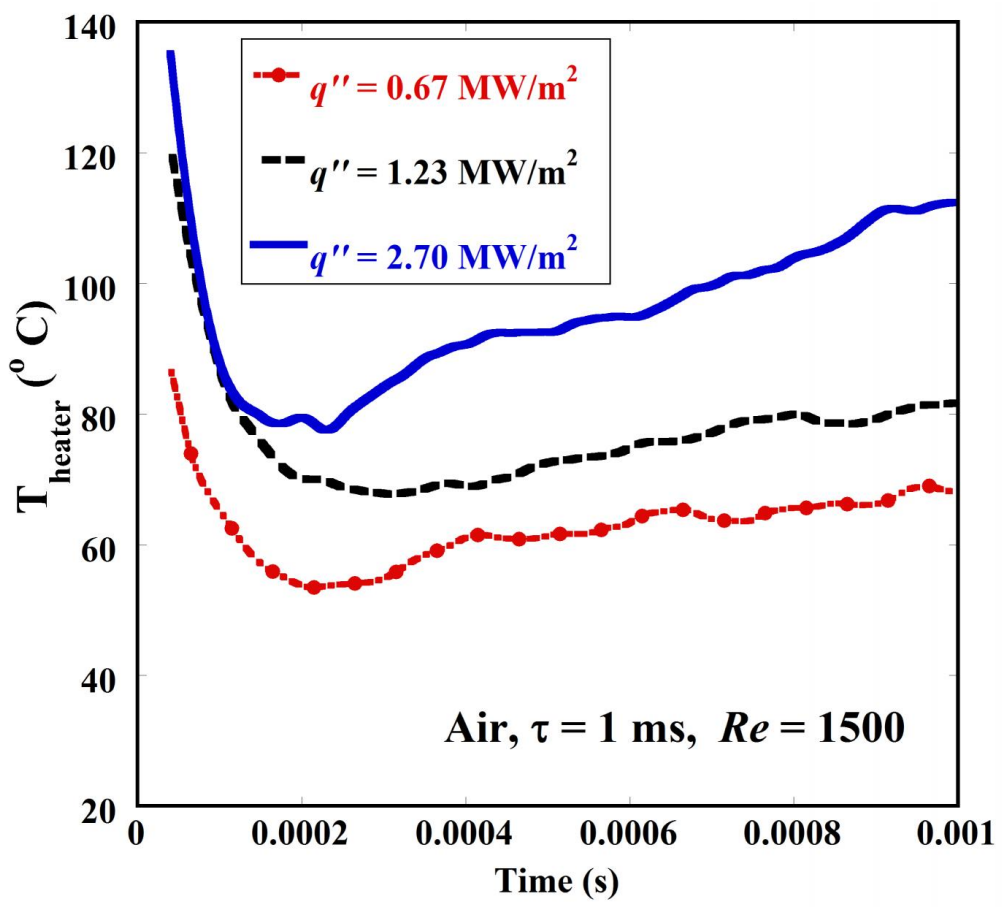

Figure 13: Effects of pulse amplitude on heater temperature response for air

A temperature overshoot was observed. The initial conduction rise was followed by a decrease in the heater temperature. The subsequent temperature rise depended on the applied heat flux. A similar temperature overshoot was observed by Jiang et al. [2, 21]. High frequency data acquisition needs to be carried out to accurately determine the initial temperature dynamics and temperature overshoot in future studies. 


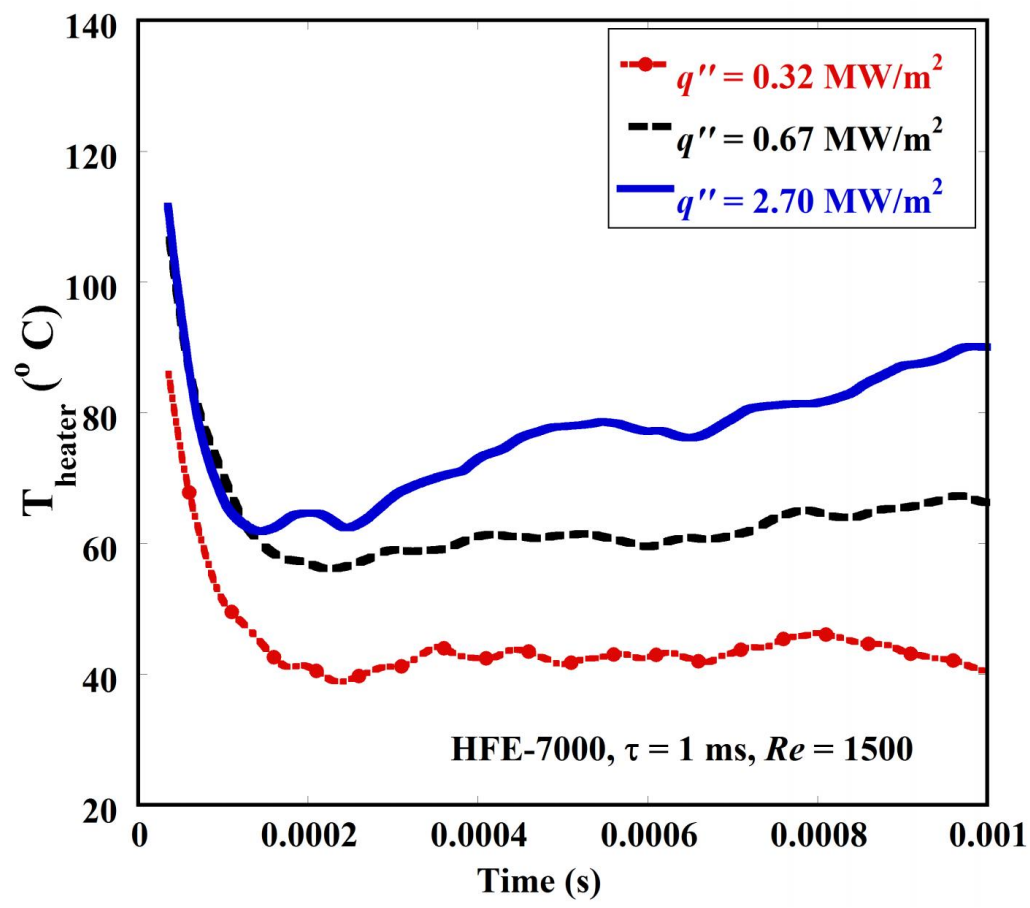

Figure 14: Effects of pulse amplitude on heater temperature response for HFE-7000

\subsubsection{Effects of Reynolds number}

Reynolds number has a minimal effect on the heater temperature response and is shown in Fig. 15 and Fig. 16 for air and HFE-7000, respectively.

The small variations in temperature were within limits of experimental uncertainty. At these time scales, heat transfer was dominated by conduction rather than convection. Therefore, the effects of Reynolds number were negligible. 


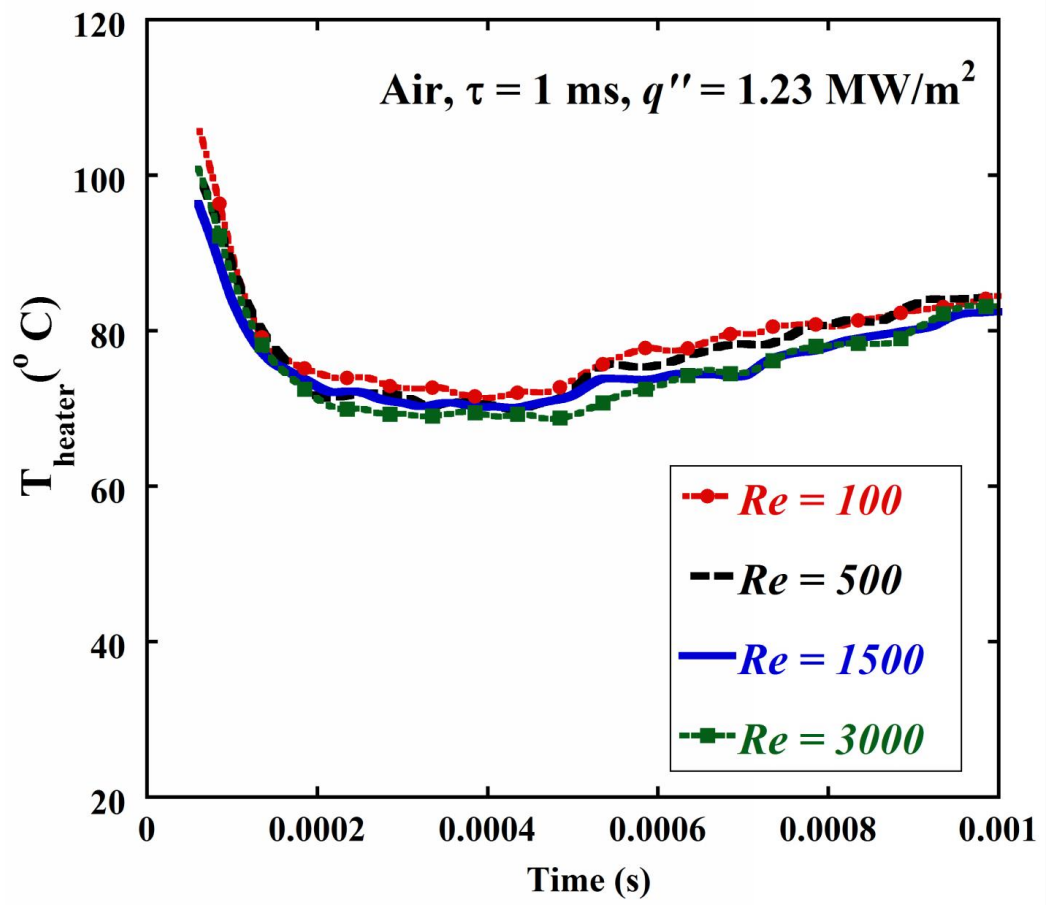

Figure 15: Effects of Reynolds number on heater temperature response for air 


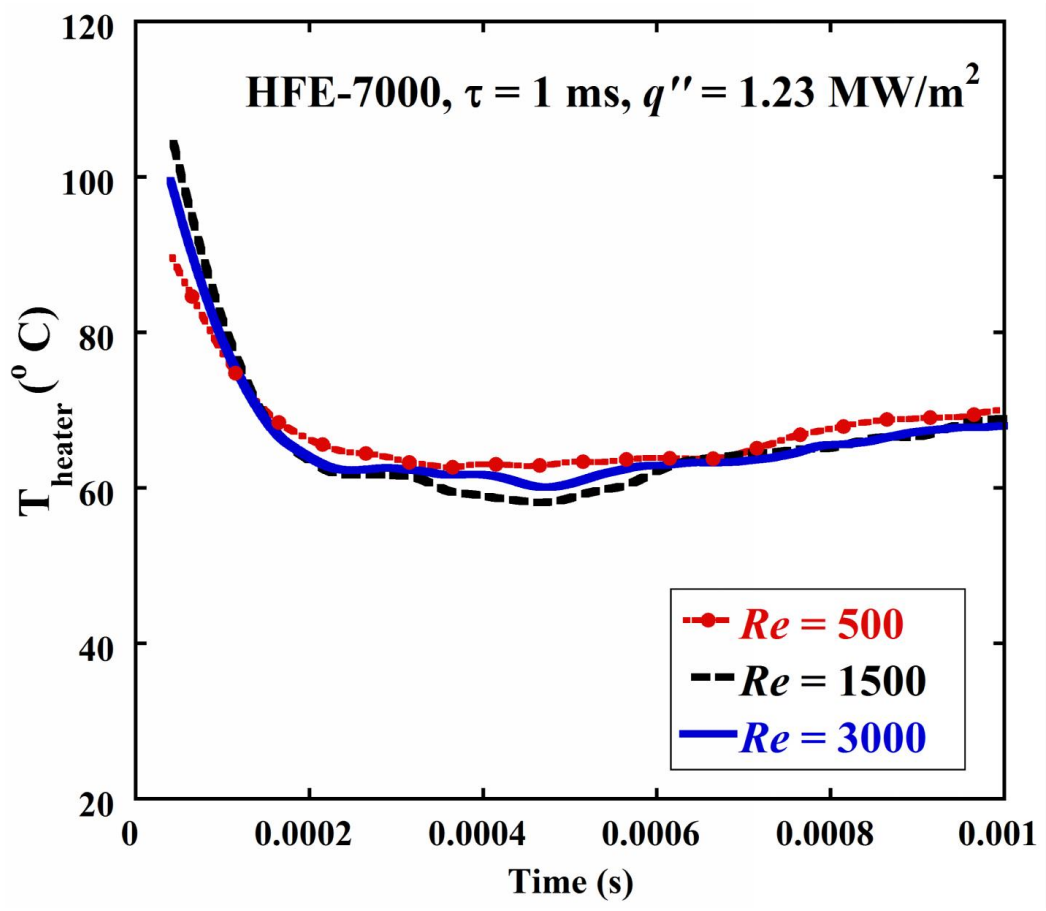

Figure 16: Effects of Reynolds number on heater temperature response for HFE7000 


\subsection{Effects of pulse width}

Total energy supplied over a time period depended on both pulse amplitude and pulse width. Heater temperature increased with increasing pulse width until the pulse width was long enough for the system to reach steady state. The effects of pulse width variations on the heater temperature response are shown in Fig. 17 and Fig. 18 for air and HFE-7000, respectively.

Pulse width itself just extended the temperature profile over time but it influenced the effects of other parameters. If the pulse width was long enough, mass flux started influencing the temperature profile as convection effects became important. For a short one millisecond pulse, Reynolds number did not significantly affect the heater temperature (Fig. 15 and Fig. 16) but for long pulses $(\approx 1 s)$, mass flux influence was significant (Fig. 7 and Fig. 8). For the same energy input, the temperature was higher for a short pulse with large amplitude than a long pulse with a smaller heat input (Fig. 19 and Fig. 20). The temperature response of the heater was dependent on the heating rate, which was higher for a shorter pulse.

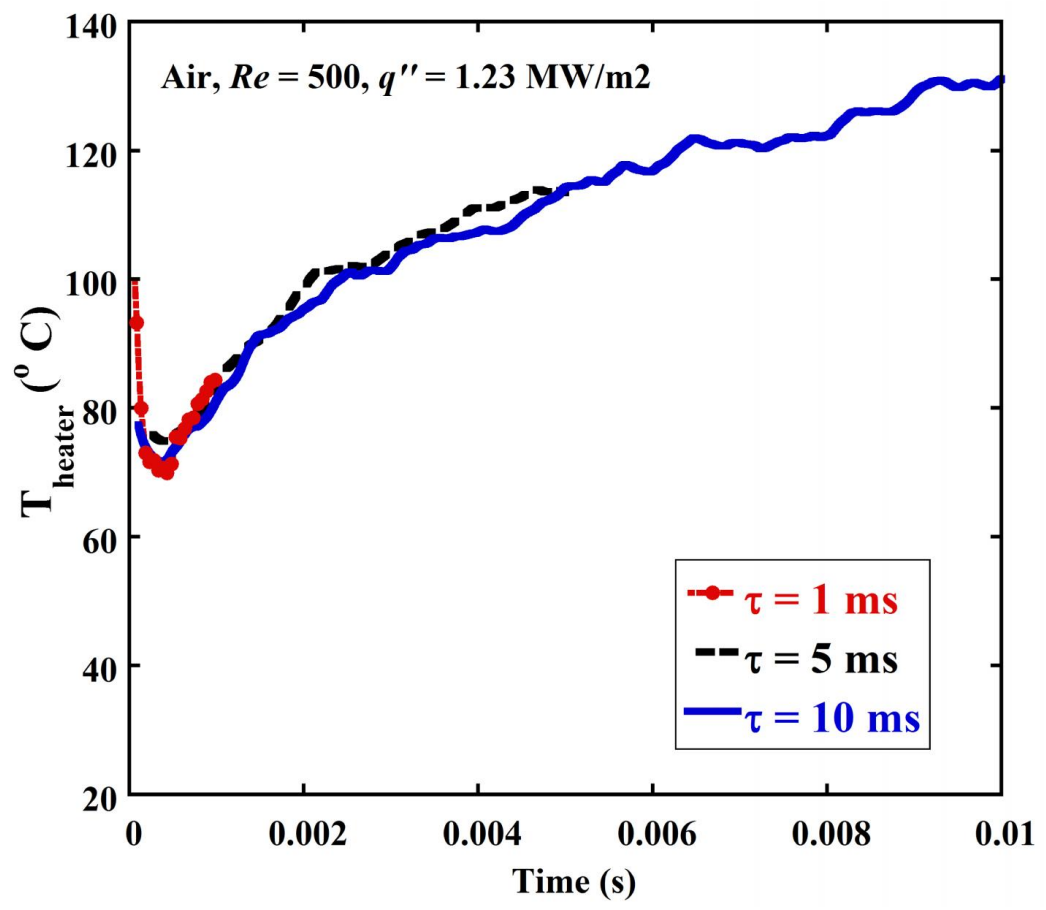

Figure 17: Effects of pulse width on heater temperature response for air 


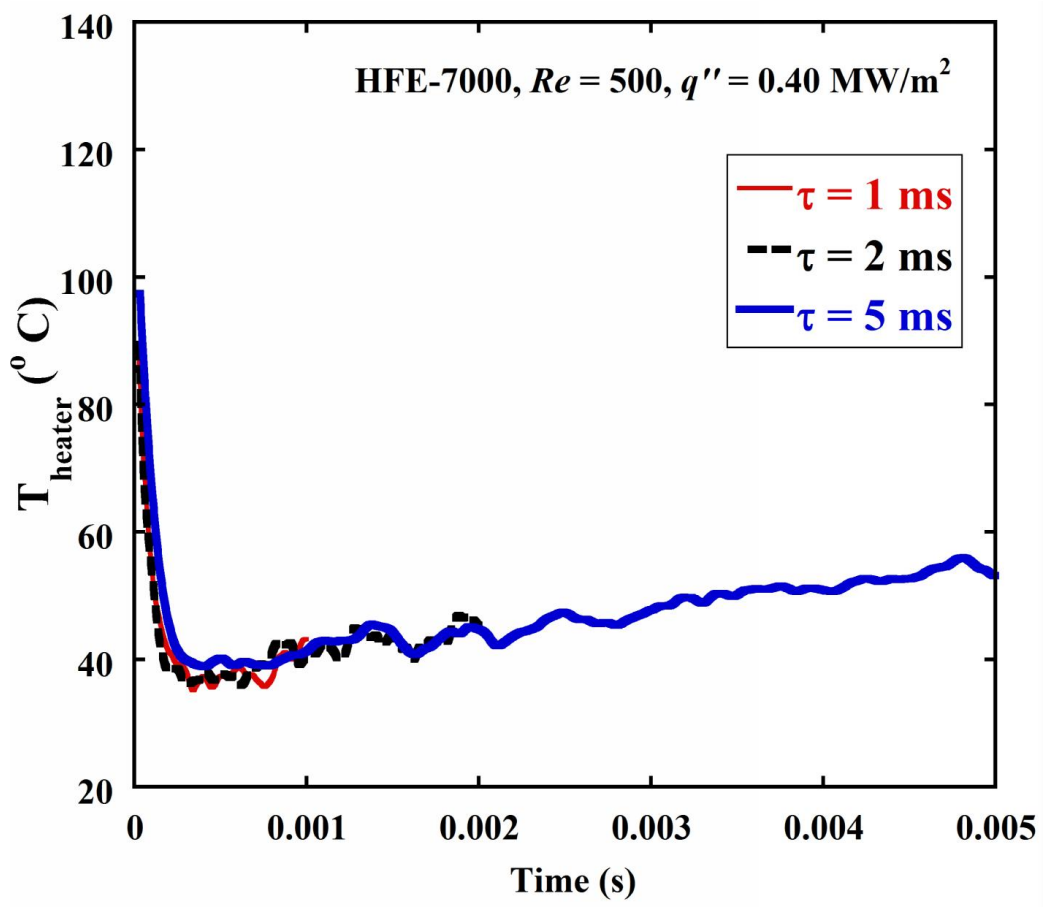

Figure 18: Effects of pulse width on heater temperature response for HFE-7000 


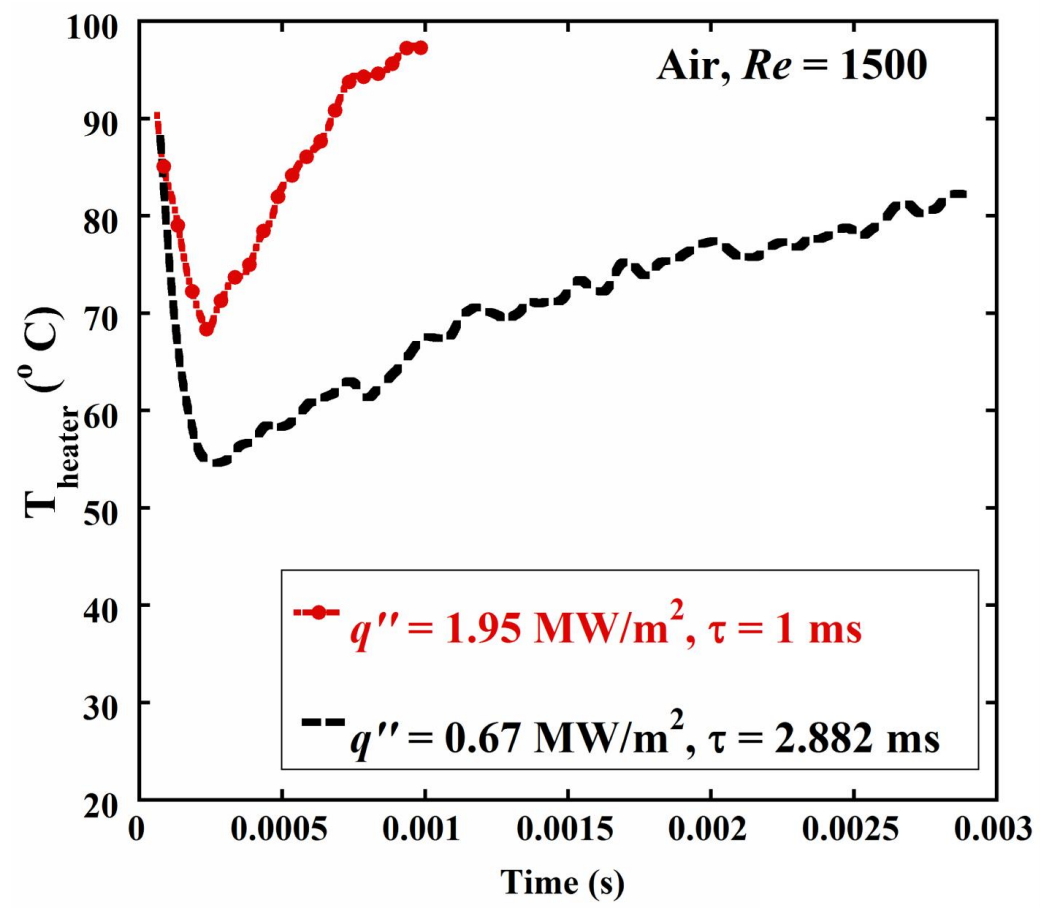

Figure 19: Combined effects of pulse width and pulse amplitude on heater temperature response for air 


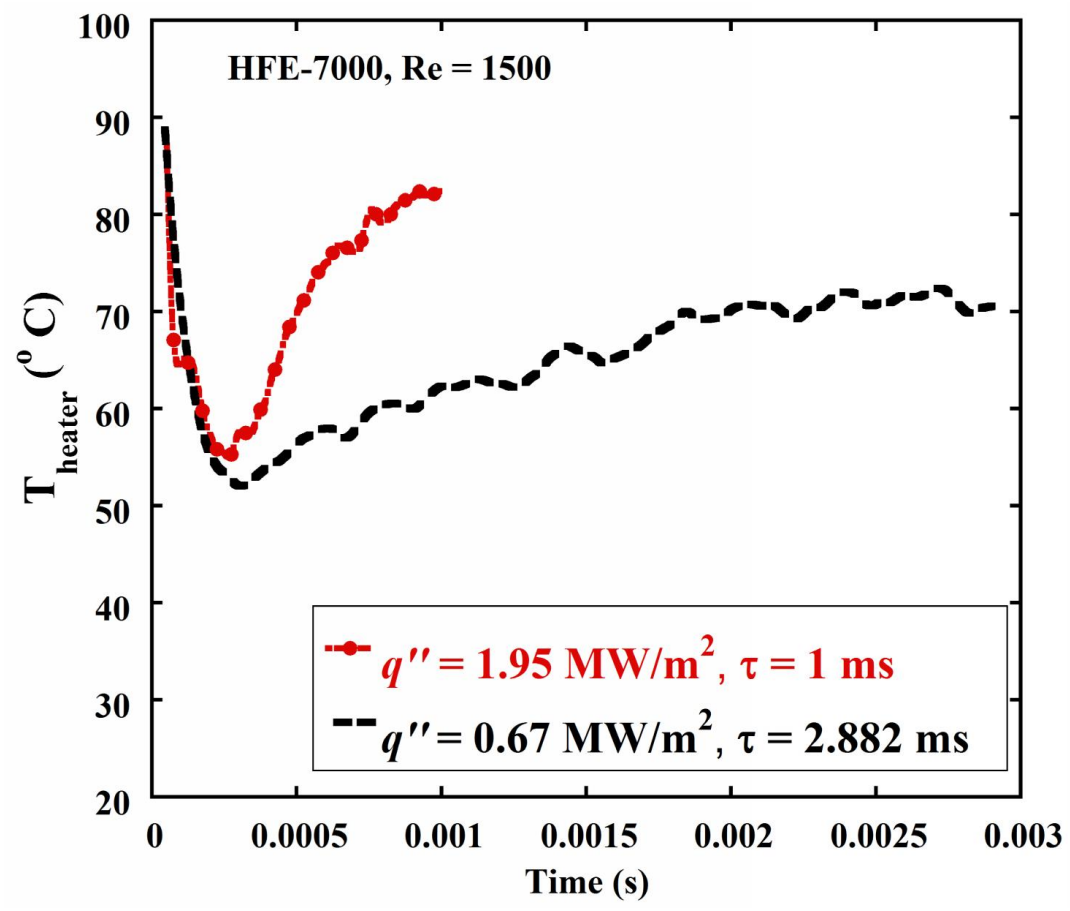

Figure 20: Combined effects of pulse width and pulse amplitude on heater temperature response for HFE-7000 


\subsection{Effects of pulse waiting period}

For a rectangular pulse, duty cycle is given by the ratio of the high (on) period to the total time period. The time period is given by the sum of pulse width and pulse waiting period. The high period is defined as pulse width while the low period is defined as the pulse waiting period in this study. A shorter time period results in a higher pulse frequency. Since the pulse width is determined by process requirements, a shorter time period could be obtained by keeping the pulse waiting period short. The minimum pulse waiting period is the time required to cool the system back to initial conditions to prevent temperature cascading effects. The pulse waiting period should be sufficiently long to cool the system back to the initial state to ensure that the system response to each subsequent pulse was not influenced by the preceding pulses.

In Fig. 21, at high duty cycles, the system does not get sufficient time to cool to its initial state. But at long waiting periods or low duty cycles, the temperature profile in response to the second pulse was similar to that of the first pulse. This was because the system had time to cool to the initial condition. In the present set of experiments, hardware limitations prevented investigation at very low duty cycles, and, hence, the initial conditions could not be replicated exactly.

For lower Reynolds number, convective cooling effects were reduced and, hence, the system required a longer waiting period to reach the same initial condition. The temperature rise in response to the pulse was also higher. For these reasons, for the same waiting period, the differences in temperature profile in response to the two pulses were higher at lower Reynolds number (Fig. 22). 


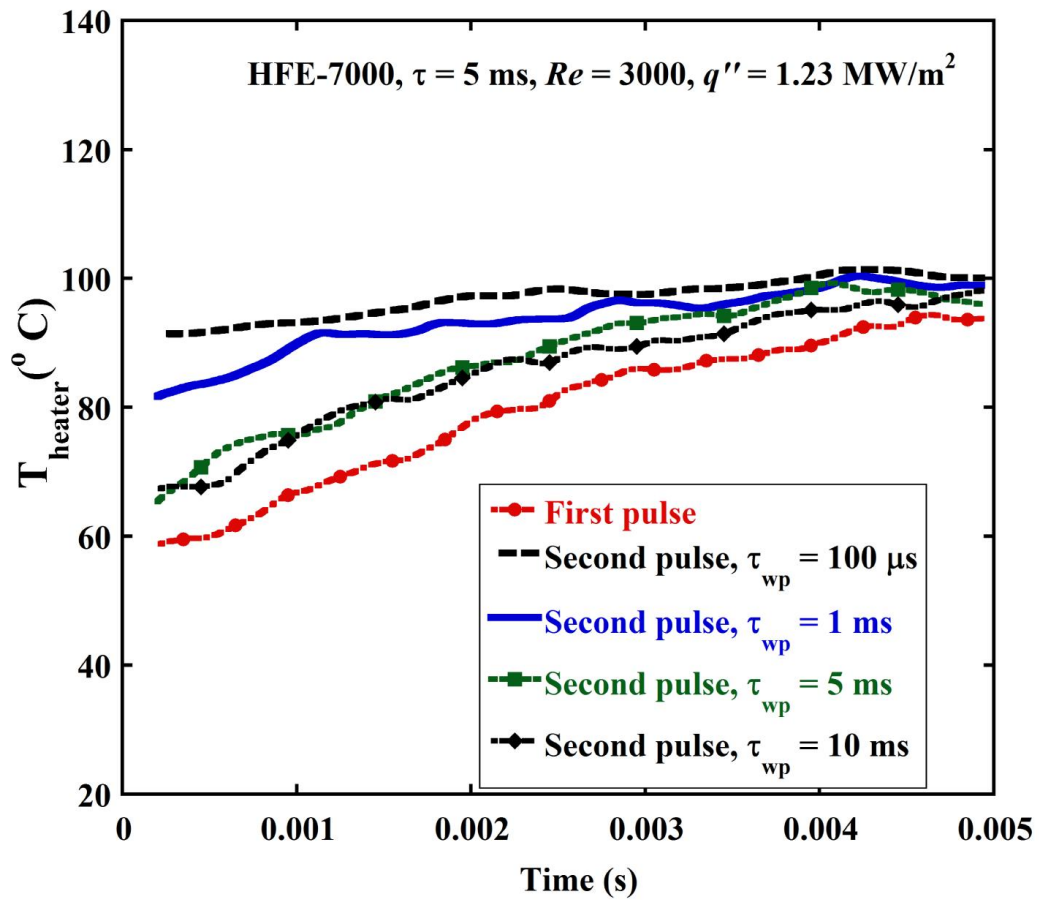

Figure 21: Effects of duty cycle variation (HFE-7000 at $R e=3000 ; \tau=5 \mathrm{~ms}$, and $\left.q^{\prime \prime}=1.23 \mathrm{MW} / \mathrm{m}^{2}\right)$ 


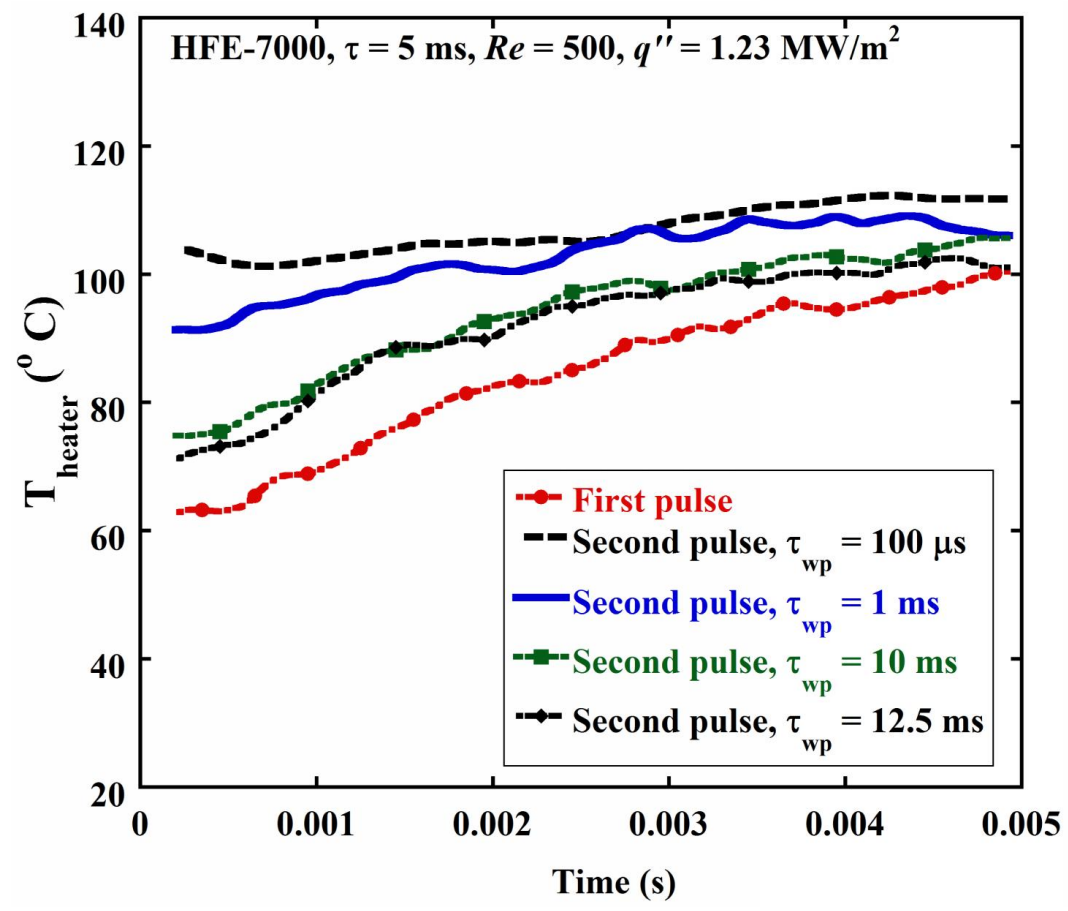

Figure 22: Effects of duty cycle variation (HFE-7000 at $R e=500 ; \tau=5 \mathrm{~ms}$, and $\left.q^{\prime \prime}=1.23 \mathrm{MW} / \mathrm{m}^{2}\right)$ 


\section{Summary}

In this study, temperature response of the microsystem was investigated for a step change in heat flux and square wave pulsed heat input. Experimental data were obtained for transient wall heat fluxes at small time scales (ms - s) and high mass fluxes. There has been only a few experimental studies $[2,21]$ at microscale for single-phase flow under transient heat loads but they were for inlet heating conditions in parallel microchannel heat sinks with deionized water as the test fluid. In the present work, air and HFE-7000 were the test fluids. The effects of different parameters such as mass flux, heat flux, and fluid properties were identified on the transient temperature response of the microsystem. The present work investigated the effects of pulse amplitude, pulse width, and pulse frequency on the system temperature response. The major findings obtained in this work are listed as follows:

- The heater temperature response was characterized by a rapid rise due to conduction at the beginning of the transient followed by slower convection dynamics until the heater temperature reached steady state. Higher heat flux resulted in higher surface temperatures both at steady state and during the transient part of the temperature response.

- The effects of mass flux or Reynolds number on the heater temperature response was more complex. Convection effects take time to come into effect. In the initial part of the temperature rise, mass flux did not affect the heater temperature response. However, at steady state, higher Reynolds number resulted in lower surface temperatures.

- Fluid properties like thermal conductivity, thermal diffusivity, and Prandtl number had a significant effect on the heater temperature response. The surface temperature was lower for HFE-7000 compared to air due to the superior thermal properties of the former.

- The temperature response of the system was slower when convection effects became dominant. Ignoring higher order dynamics, the convection temperature response could be modeled as a first-order system, which is characterized by its time constant. Time constant of the system decreased with increasing Reynolds number as heat transfer coefficients increased with increasing Reynolds number. Time constant for HFE-7000 showed a 50\% decrease compared to that for air. 
- For the pulsed input study, heat fluxes as well as heating rates were higher. The data were sampled at a higher rate. High frequency dynamics were identified at the beginning with the heater temperature exhibiting overshoot characteristics similar to the ones observed in the Jiang et al. study [2, 21].

- Longer pulse width resulted in higher surface temperatures for the same heat flux. Longer pulse width allowed convection effects to come into play. Shorter pulse and higher amplitude resulted in higher temperatures compared to longer pulse and lower amplitude for the same energy input.

- The pulse waiting period defined the duty cycle and should be at least long enough to ensure that the system returned to the initial state before the next pulse. The pulse waiting period is longer for lower mass fluxes and higher heat fluxes and longer pulse widths.

\section{Acknowledgement}

This work was supported by the Office of Naval Research (ONR) under the Multidisciplinary University Research Initiative (MURI) Award GG10919

entitled "System-Level Approach for Multi-Phase, Nanotechnology-Enhanced Cooling of High-Power Microelectronic Systems." 
[1] D. Bunce, S. Kandlikar, Transient response of heat exchangers, in: Proceedings of the second ISHMT-ASME Heat and Mass Transfer Conference, Surathkal, India, 1995.

[2] L. Jiang, M. Wong, Y. Zohar, Unsteady characteristics of a thermal microsystem, Sensors and Actuators 82 (2000) 108-113.

[3] S. Olek, E. Elias, E. Wacholder, S. Kaizerman, Unsteady conjugated heat transfer in laminar pipe flow, International Journal of Heat and Mass Transfer 34 (1991) 1443-1450.

[4] R. O. C. Guedes, M. N. Ozisik, Transient heat transfer in simultaneously developing channel flow with step change in inlet temperature, International Journal of Heat and Mass Transfer 37 (1994) 2699-2706.

[5] M. A. Al-Nimr, M. A. I. El-Shaarawi, Analytical solutions for transient conjugated heat transfer in parallel plate and circular ducts, International Communications in Heat and Mass Transfer 19 (1992) 869-878.

[6] W. M. Yan, T. F. Lin, Unsteady conjugated heat transfer in laminar pipe flows with step change in ambient temperature, International Communications in Heat and Mass Transfer 14 (1987) 699-707.

[7] W. M. Yan, Y. L. Tsay, T. F. Lin, Transient conjugated heat transfer in laminar pipe flows, International Journal of Heat and Mass Transfer 32 (1989) 775-777.

[8] Ş. Bilir, Transient conjugated heat transfer in pipes involving twodimensional wall and axial fluid conduction, International Journal of Heat and Mass Transfer 45 (2002) 1781-1788.

[9] Ş. Bılır, Laminar flow heat transfer in pipes including two-dimensional wall and fluid axial conduction, International Journal of Heat and Mass Transfer 38 (1995) 1619-1625.

[10] Ş. Bilir, A. Ateş, Transient conjugated heat transfer in thick walled pipes with convective boundary conditions, International Journal of Heat and Mass Transfer 46 (2003) 2701-2709.

[11] T. F. Lin, J. C. Kuo, Transient conjugated heat transfer in fully developed laminar pipe flows, International Journal of Heat and Mass Transfer 31 (1988) 1093-1102. 
[12] J. Sucec, Unsteady heat transfer between a fluid, with time varying temperature, and a plate: An exact solution, International Journal of Heat and Mass Transfer 18 (1975) 25-36.

[13] J. Sucec, A. M. Sawant, Unsteady, conjugated, forced convection heat transfer in a parallel plate duct, International Journal of Heat and Mass Transfer 27 (1984) 95-101.

[14] J. Sucec, Unsteady forced convection with sinusoidal duct wall generation: The conjugate heat transfer problem, International Journal of Heat and Mass Transfer 45 (2002) 1631-1642.

[15] D. J. Schutte, M. M. Rahman, A. Faghri, Transient conjugate heat transfer in a thick-walled pipe with developing laminar flow, Numerical Heat Transfer 21 (1992) 163-186.

[16] W.-M. Yan, Unsteady conjugated heat transfer in turbulent channel flows with convection from the ambient, International Journal of Heat and Mass Transfer 38 (1995) 2101-2108.

[17] A. M. Morega, J. V. C. Vargas, A. Bejan, Optimization of pulsating heaters in forced convection, International Journal of Heat and Mass Transfer 38 (1995) 2925-2934.

[18] G. Joyce, H. M. Soliman, Analysis of the transient single-phase thermal performance of micro-channel heat sinks, Heat Transfer Engineering 30 (2009) 1058-1067.

[19] J. Rujano, M. Rahman, Transient response of microchannel heat sinks in a silicon wafer, Journal of Electronic Packaging 119 (1997) 239-246.

[20] P. C. Rao, M. M. Rahman, Transient conjugate heat-transfer model for circular tubes inside a rectangular substrate, Journal of thermophysics and heat transfer 20 (2006) 122-134.

[21] L. Jiang, M. Wong, Y. Zohar, Transient temperature performance of an integrated micro-thermal system, Journal of Micromechanics and Microengineering 10 (2000) 466-476.

[22] S. Basu, B. Werneke, Y. Peles, M. K. Jensen, Transient microscale flow boiling heat transfer characteristics of HFE-7000, International Journal of Heat and Mass Transfer 90 (2015) 396-405. 
[23] E. Browne, Experimental investigation of single-phase and flow boiling, submerged, and confined microjet array heat transfer, Ph.D. thesis, Department of Mechanical, Aerospace, and $\mathrm{Nu}-$ clear Engineering, Rensselaer Polytechnic Institute, 2010. URL: http: //gradworks . umi. com/34/48/3448405.html.

[24] S. Basu, Transient heat transfer characteristics of a thermal microdevice, Ph.D. thesis, Department of Mechanical, Aerospace, and Nuclear Engineering, Rensselaer Polytechnic Institute, 2013. URL: http://digitool.rpi .edu:8881/dtl_publish/47/170217.html.

[25] C. T. Avedisian, W. S. Osborne, F. D. McLeod, C. M. Curley, Measuring bubble nucleation temperature on the surface of a rapidly heated thermal ink-jet heater immersed in a pool of water, Proceedings of the Royal Society of London. Series A: Mathematical, Physical and Engineering Sciences 455 (1999) 3875-3899.

[26] S. J. Kline, F. A. McClintock, Describing uncertainties in single-sample experiments, Mechanical Engineering 75 (1953) 3-8. 